\title{
Teresa L. Knott, AHIP, Medical Library Association President, 2016-2017
}

DOI: http://dx.doi.org/10.3163/1536-5050.104.3.002

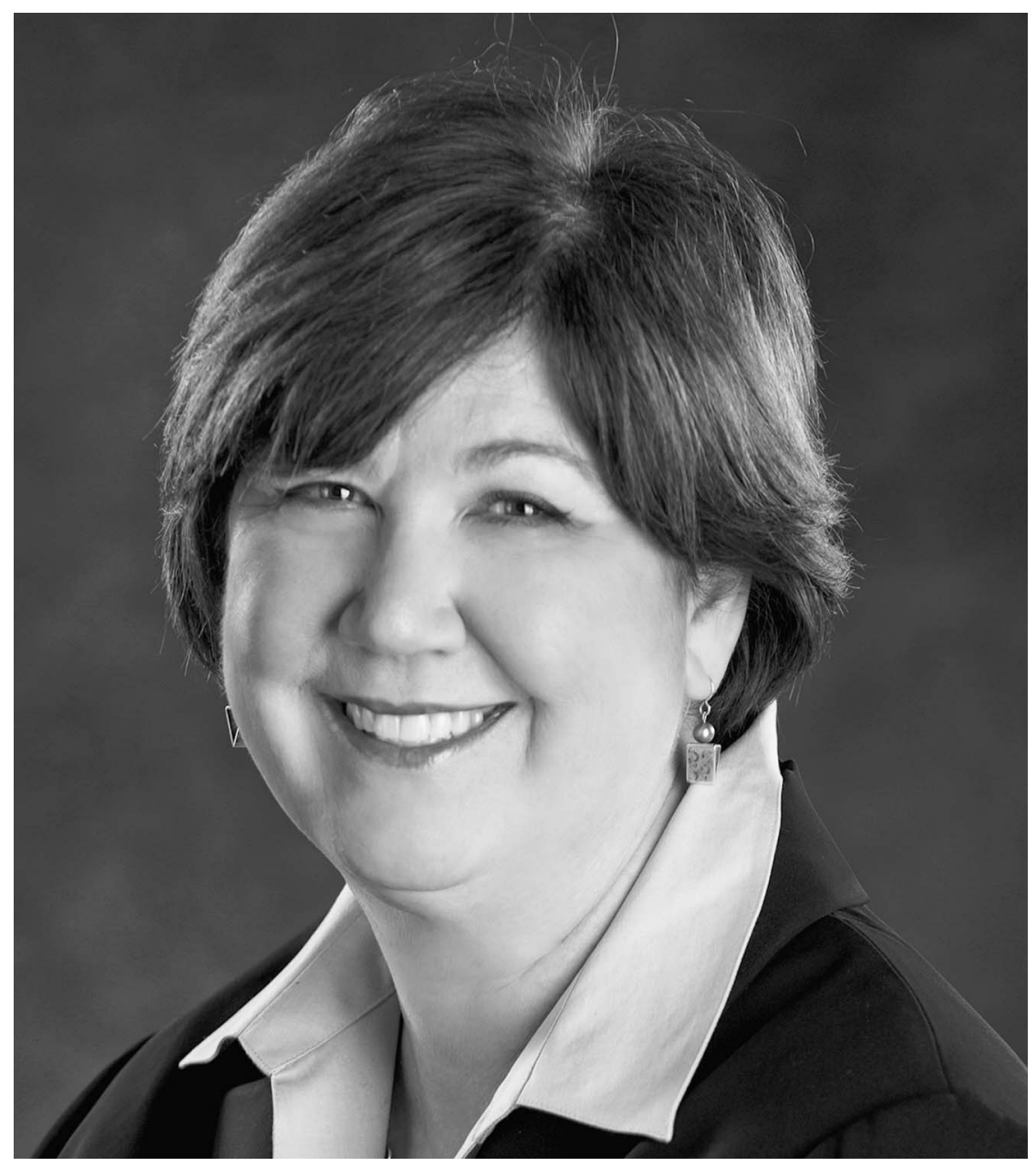

One October night in 2000, six medical librarians drove up a mountain outside of El Paso, Texas, to see the lights. I sat immediately behind Teresa L. Knott, AHIP, the driver. On the way back down the mountain, I noticed that she occasionally used the van's handbrake while continuing to answer our questions about the sights. Another passenger, Linne' Girouard, remembers that Teresa's responses were informative but brief and perhaps less chatty than usual, which Linne' relieved that it was Teresa driving and not one of the rest of us.

Many Medical Library Association (MLA) members identify Teresa with the Mid-Atlantic region, where she is director of the Tompkins-McCaw Library for the Health Sciences at the Virginia Commonwealth University (VCU), Richmond, Virginia, since 2009, and, before that, deputy director of the Health Sciences and Human Services Library (HSHSL) at the University of Maryland, Baltimore, but her oldest friends in MLA think of her as a Texan or New Mexican - or perhaps a bit of both.

Born in Abilene, Texas, where her father was stationed at Dyess Air Force Base, Teresa's family moved to Casper, Wyoming, then to Farmington, New Mexico, in the northwest "Four Corners" area of the state, before she celebrated her first birthday. When she was ten, they moved again to Hobbs, on the eastern edge of New Mexico. Except for her time at the University of New Mexico for her undergraduate education and at the University of Oklahoma, where she received her master of library science degree, Teresa spent the next thirty-five years near the Texas-New Mexico border. Her farthest foray from the border during that time was the two years she spent in Lubbock, Texas, less than seventy miles from New Mexico, in her first professional position at the Texas Tech University Library of the Health Sciences. She describes her hometown of Hobbs, situated on the border, as "more West Texas than New Mexico" and her adopted hometown of El Paso, 
farther south and west than Hobbs, but also on the border, as more New Mexican than Texan.

\section{FIRST LIBRARY WORK}

Teresa's first taste of library work came when she attended New Mexico Junior College in Hobbs. There, she rotated from circulation to serials to special collections and became familiar with "filing above the rod"-the practice of placing cards in the card catalog in their proper place, but resting on top of the retaining rod, which was pulled out and inserted through the holes on the card after the filing was checked by a senior staff member.

After transferring to the University of New Mexico (UNM) in Albuquerque, she worked in government documents and archives but intended to become a physical therapist. At some point during her time at UNM, she discovered the world of medical librarianship, and her career goal changed. Her parents moved to Oklahoma during her senior year of college, so she applied to the library program at the University of Oklahoma (OU). Unfortunately, her first semester at OU coincided with the last semester of the faculty member who taught health sciences librarianship.

The lack of coursework did not deter her from applying for her first professional position at the Texas Tech University Library of the Health Sciences in Lubbock. Her strong science background, including courses in anatomy and physiology from the period when she majored in physical therapy, was no doubt as useful as library school coursework would have been.

\section{BECOMING A MEDICAL LIBRARIAN}

Charles W. Sargent, AHIP, FMLA, was the director in Lubbock when Teresa was hired there as a reference librarian. His first impression of her was that she made friends easily and was well liked. Two years later, he was happy to appoint her as the associate director of the library at what was then Texas Tech's Regional Academic Health Center in El Paso and is now Texas Tech University Health Sciences Center El Paso. Although she remained there for almost twenty years, Dr. Sargent says he knew that she was meant for greater things, including becoming "one of those who was making MLA work."

JoAnn Van Schaik, currently interim executive director of the Calder Memorial Library at the University of Miami Miller School of Medicine, was a librarian at Texas Tech with Teresa. She recalls that Teresa possesses strong leadership and managerial skills. At the same time, she is a superb listener who never forgets a person and is a fun-loving, steadfast friend. She is also a thoughtful and sincere advisor, deliberate in her responses, which always contain a strong dose of common sense, JoAnn Van Schaik added.

Librarians were not the only people at Texas Tech who were impressed by Teresa. While there, she met J. Manuel de la Rosa, now provost and vice president of academic affairs at Texas Tech University Health Sciences Center El Paso. In addition to being what he calls a "good librarian...serving as an advocate for additional funding, space, and resources," Teresa also served as an advisor to many younger faculty members in their mission to learn the academy's culture and processes. She helped plan and execute a faculty development course aimed at expanding scholarly activities and attaining academic goals to assist faculty in fulfilling the campus's mission.

During her time in El Paso, Teresa became an active member of the South Central Chapter (SCC) of MLA, serving on and chairing numerous committees and serving as 2002-2004 Chapter Council representative. In 2000, she served as SCC president and coordinated the annual meeting that year, which was coincidentally in El Paso-which explains why we were all in that van on the mountain with her.

\section{FROM THE SOUTHWEST TO MARYLAND}

It was a surprise to her friends in SCC when Teresa announced in 2004 that she was leaving El Paso to become deputy director of the HSHSL at University of Maryland, Baltimore. We knew she had the abilities needed for the position; we just never imagined she would leave El Paso.

M.J. Tooey, AHIP, FMLA, executive director of the HSHSL, recalls hearing about Teresa through her association with SCC and may have first met her at an Armadillo Ball, SCC's annual party at the MLA annual meeting. Struck by her energy and enthusiasm, M.J. felt that Teresa would be a perfect fit for the role of deputy director because the library needed a major reorganization, a new strategic plan, and expansion of community and university outreach and visibility. In addition, she would have oversight of the library's technology department. M.J. said that Teresa's inquisitiveness, fearlessness in stepping out of her comfort zone, and adaptability led to success in the position. M.J. also pointed out 
that Teresa's decisiveness and willingness to share her opinions, listen, and even change her mind when necessary are excellent qualities for a library administrator and for the president of MLA. Teresa is exactly the person you want around when a decision needs to be made.

Alexa Mayo, AHIP, another colleague from the HSHSL, recalls Teresa's adaptability and flexibility. She describes Teresa as "a critical thinker with strong analytical skills," who brings "creativity and vision to her projects and to the challenges she faces." According to Alexa Mayo, Teresa is a strong communicator who explains her viewpoints clearly and honestly: "She gets her message across in a direct way, often with a twinkle in her eye. She is not afraid to tell stories to lighten the mood or to illustrate her point."

\section{THEN TO VIRGINIA}

In 2005-2006, Teresa took part in the National Library of Medicine/ Association of Academic Health Sciences Libraries Leadership Fellows Program. Her program mentor, Karen Brewer, FMLA, former director of the New York University Health Sciences Libraries, witnessed Teresa's gift for working with people at all levels of the library and the greater institution. She said that it was clear that Teresa "needed very little additional preparation" to take the next step up, and in 2009, after a little more than four years in Baltimore, Teresa accepted the position of director of TompkinsMcCaw Library for the Health Sciences and associate university librarian and associate professor at VCU in Richmond.

VCU University Librarian John Ulmschneider described Teresa's "profound understanding of insti- tutional dynamics and staff engagement with mission," which allows her influence to reach beyond the Tompkins-McCaw Library to include leadership responsibilities extending across the entire library system. At VCU, Teresa's portfolio includes not just the health sciences, but also library-wide responsibility for data curation, interlibrary loan, and the university archives. She is also the library system's chief liaison to the campus Office of Research and Innovation. He describes how her "work in building staff engagement and commitment, and particularly in highlighting the myriad accomplishments of staff throughout the library system, has been instrumental in tapping the full potential of staff talent and in creating an energizing excitement about the library's work."

Lynne Underwood Turman, head of the Tompkins-McCaw Library's collections unit, characterizes Teresa as an advocate and a collaborator who is always seeking creative solutions to problems. She also likens Teresa to her beloved Broadway musicals: energetic, harmonious, and memorable, saying, "She shines in the leading role but is equally comfortable as part of the ensemble cast. Her high levels of energy and sense of sharp direction should make for a show-stealing performance on the national level."

Shannon Demona Jones, now director of Libraries at the Medical University of South Carolina and a former colleague at TompkinsMcCall Library, calls Teresa one of her "absolute favorite librarians" - with excellent skills in communication, negotiation, collaboration, and advocacy-who "brings her authentic self to every interaction, does not take things personally, and likes to laugh."
One of Teresa's strengths, according to Margaret Henderson, AHIP, director of research data management at the VCU Libraries, is that she expects everyone to do their best but "does not expect miracles." JoAnn Van Shaik also mentions that Teresa truly believes that what every member of the library staff does is important and by conveying this, inspires them to work up to the expectations she has for them.

Teresa's ability to relate to others, both personally and professionally, is a much repeated theme. JoAnn Van Shaik describes Teresa's compassion in supporting her during a time of personal tragedy and M.J. Tooey mentions Teresa's loyalty to her family and to her friends across the country. Shannon Jones and Margaret Henderson both describe her support for them during times of change. Teresa's encouragement allowed Shannon Jones to make the decision to pursue her goal of becoming a library director. Similarly, Teresa supported Margaret Henderson's interest in data and bioinformatics, which led to her current position. J. Manuel de la Rosa remembers Teresa providing valuable advice and mentorship to faculty members at Texas Tech Health Sciences Center El Paso, in research, education, and even in clinical activity.

Michelle Kraft, AHIP, senior medical librarian at Cleveland Clinic Alumni Library and current MLA president, who served with Teresa as cochair of the National Program Committee for MLA '12, describes her as someone who has consistently involved new and emerging librarians in MLA activities, blending those with less experience with more senior members.

Universally, those who know Teresa look forward to her MLA presidency, knowing that she will 
bring to the position what John Ulmschneider describes as "optimistic vigor" and what M.J. Tooey describes more simply as "enthusiasm: one of Teresa's key qualities." Shannon Jones points out that "the same qualities that made her an effective library director will make her equally impactful as the president of MLA." Expecting the MLA president to be a forward thinker, a change agent, and an advocate for all levels of the membership, she believes that
Teresa "will bring the passion, patience, and persistence needed for a successful MLA presidency." Michelle Kraft points out that "Teresa is also somebody who doesn't take 'no' for answer. She looks at different solutions and ways around brick walls."

Personally, I am thrilled that Teresa is the new president of MLA. For many years, I have depended on her wisdom and optimism and have looked forward to her sense of humor and her big smile. To quote Karen Brewer, "How wonderful for MLA, that as our leader, Teresa will bring a positive spirit that leaves in its wake a 'can do' attitude coupled with the feeling that you have a real friend at the helm."

Janna C. Lawrence, MLIS, AHIP, janna-lawrence@uiowa.edu, Deputy Director, Hardin Library for the Health Sciences, University of Iowa, Iowa City, IA 